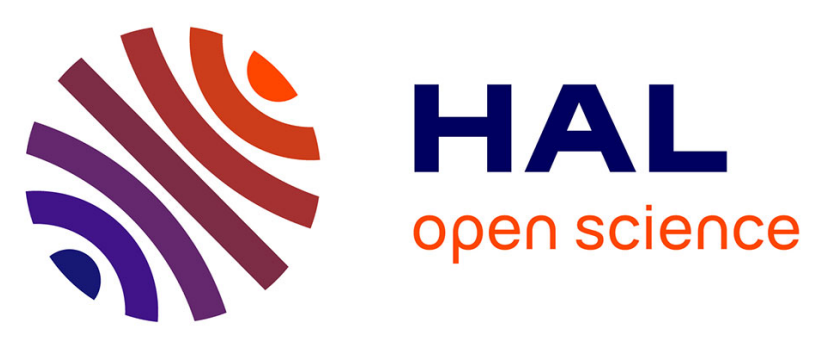

\title{
Homogeneous triacylglycerol tracers have an impact on the thermal and structural properties of dietary fat and its lipolysis rate under simulated physiological conditions
}

Sabine Danthine, Cécile Vors, Damien Agopian, Annie Durand, Romain

Guyon, Frédéric Carrière, Carole Knibbe, Marion Létisse, Marie-Caroline

Michalski

\section{To cite this version:}

Sabine Danthine, Cécile Vors, Damien Agopian, Annie Durand, Romain Guyon, et al.. Homogeneous triacylglycerol tracers have an impact on the thermal and structural properties of dietary fat and its lipolysis rate under simulated physiological conditions. Chemistry and Physics of Lipids, 2019, 225, 10.1016/j.chemphyslip.2019.104815 . hal-02326893

\section{HAL Id: hal-02326893 https://hal.science/hal-02326893}

Submitted on 16 Nov 2020

HAL is a multi-disciplinary open access archive for the deposit and dissemination of scientific research documents, whether they are published or not. The documents may come from teaching and research institutions in France or abroad, or from public or private research centers.
L'archive ouverte pluridisciplinaire $\mathbf{H A L}$, est destinée au dépôt et à la diffusion de documents scientifiques de niveau recherche, publiés ou non, émanant des établissements d'enseignement et de recherche français ou étrangers, des laboratoires publics ou privés. 


\title{
Preprint of DOI: 10.1016/j.chemphyslip.2019.104815 \\ Homogeneous triacylglycerol tracers have an impact on the thermal and structural properties of dietary fat and its lipolysis rate under simulated physiological conditions
}

\author{
Sabine DANTHINE ${ }^{1}$ Cécile VORS,${ }^{2,3}$ Damien AGOPIAN,${ }^{2}$ Annie DURAND,${ }^{2}$ Romain GUYON, ${ }^{2}$ \\ Frédéric CARRIERE, ${ }^{4}$ Carole KNIBBE, ${ }^{2,5}$ Marion LETISSE, ${ }^{2}$ \\ and Marie-Caroline MICHALSKI ${ }^{2,3, *}$
}

${ }^{1}$ Science des Aliments et Formulation, Gembloux Agro-Bio Tech, ULiège, Gembloux, Belgique.

${ }^{2}$ Univ-Lyon, CarMeN laboratory, INRA UMR1397, INSERM U1060, INSA-Lyon, Université Claude Bernard Lyon 1, F-69621 Villeurbanne, France.

${ }^{3}$ Centre de Recherche en Nutrition Humaine Rhône-Alpes (CRNH), Centre Européen pour la Nutrition et la Santé (CENS), Pierre-Bénite, France.

${ }^{4}$ Aix Marseille Université, CNRS, Bioénergétique et Ingénierie des Protéines UMR7281, Marseille, France

${ }^{5}$ Inria "Beagle" team, Antenne Lyon la Doua, F-69603 Villeurbanne, France

*Corresponding author: INRA, UMR 1397, CarMeN laboratory, IMBL Building, 15 avenue Jean Capelle, 69621 Villeurbanne cedex, France.

Tel: +33472438570 - Fax: +33472438526

E-mail address: marie-caroline.michalski@inra.fr

Author contribution:

Sabine Danthine was involved in the conception and design of the study, in acquisition, analysis and interpretation of data from physical chemical characterization of milk fat mixtures, in drafting the article, revising it critically for important intellectual content. Dr Cécile Vors was involved in the conception and design of the study, in drafting the article, revising it critically for important intellectual content. Damien Agopian was involved in acquisition, analysis and interpretation of data from in vitro digestion, in drafting the article. Annie Durand was involved in the conception and design of the study, in acquisition, analysis of data from in vitro digestion. Romain Guyon was involved in acquisition of data from in vitro digestion. Frédéric Carrière was involved in the conception of the study, in acquisition, analysis and interpretation of data of in vitro digestion, in drafting the article, revising it critically for important intellectual content. Carole Knibbe was involved in the design of the study, in acquisition, analysis and interpretation of data of in vitro digestion, in drafting the article, revising it critically for important intellectual content. Marion Letisse was involved in the design of the study, in acquisition, analysis and interpretation of data of in vitro digestion, in drafting the article, revising it critically for important intellectual content. Dr Marie-Caroline Michalski was involved in the conception and design of the study, in data interpretation, in drafting the article, revising it critically for important intellectual content and final 
approval of the version to be submitted. All authors were involved in the final approval of the version to be submitted.

\section{Funding:}

This work was supported by the Centre National Interprofessionnel de l'Economie Laitiere (CNIEL; French Dairy Interbranch Sector). CV received funding for her PhD study by INRA and CNIEL and received a Research Prize from the Foundation Nestlé France. Corman SA kindly provided the anhydrous milk fat, Lactalis R\&D provided the skim milk powder, and Sodiaal-Candia R\&D prepared and processed the skim milk. The funding agencies and ingredient providers had no role in the data analysis.

\section{Conflict of interest disclosure:}

MCM received research funding from the Centre National Interprofessionnel de l'Economie Laitière (CNIEL), Nutricia Research and Sodiaal-Candia R\&D and has consultancy activities for food and dairy companies. Other authors have no conflict of interest to declare.

Running title: Structure and digestibility of dietary fat enriched with triacylglycerol tracers.

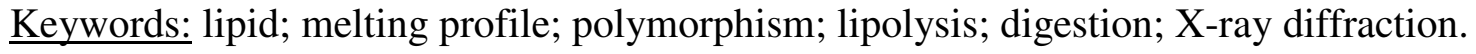

Abbreviations: AMF: anhydrous milk fat; TAG: triacylglycerol; DAG: diacylglycerol; MAG: monoacylglycerol; FA: fatty acid; FFA: free fatty acid; PPP: tripalmitin; OOO: triolein; CCC: tricaprylin; XRD: powder X-ray diffraction; DSC: differential scanning calorimetry. 


\begin{abstract}
Dietary fats are present in the diet under different types of structures, such as spread $v s$ emulsions (notably in processed foods and enteral formula), and interest is growing regarding their digestion and intestinal absorption. In clinical trials, there is often a need to add stable isotope-labeled triacylglycerols (TAGs) as tracers to the ingested fat in order to track its intestinal absorption and further metabolic fate. Because most TAG tracers contain saturated fatty acids, they may modify the physicochemical properties of the ingested labeled fat and thereby its digestion. However, the actual impact of tracer addition on fat crystalline properties and lipolysis by digestive lipases still deserves to be explored. In this context, we monitored the thermal and polymorphic behavior of anhydrous milk fat (AMF) enriched in homogeneous TAGs tracers and further compared it to the native AMF using differential scanning calorimetry and power X-ray diffraction. As tracers, we used a mixture of tripalmitin, triolein and tricaprylin at 2 different concentrations (of 1.5 and $5.7 \mathrm{wt} \%$, which have been used in clinical trials). The addition of TAG tracers modified the AMF melting profile, especially at the highest tested concentration (5.7\% wt\%). Both AMF and AMF enriched with 1.5 $\mathrm{wt} \%$ tracers were completely melted at around $37^{\circ} \mathrm{C}$, i.e. close to the body temperature, while the AMF enriched with $5.7 \mathrm{wt} \%$ tracers remained partially crystallized at this temperature. Similar trends were observed in both bulk and emulsified systems. Moreover, the kinetics of AMF polymorphic transformation was modified in the presence of tracers. While only $\beta$ ' form was observed in the native AMF, the $\beta$-form was clearly detected in the AMF containing $5.7 \mathrm{wt} \%$ tracers. We further tested the impact of tracers on the lipolysis of AMF in bulk using a static in vitro model of duodenal digestion. Lipolysis of AMF enriched with $5.7 \mathrm{wt} \%$ tracers was delayed compared that of AMF and AMF enriched with $1.5 \mathrm{wt} \%$ tracers. Therefore, low amounts of TAG tracers including tripalmitin do not have a high impact on fat digestion, but one has to be cautious when using higher amounts of these tracers.
\end{abstract}




\section{Introduction}

Many studies on the nutritional properties of dietary fats mainly take into account their quantity and/or their fatty acid composition. However, in everyday diet, lipids can be of various molecular species (mostly triacylglycerols (TAGs), but also phospholipids) and they are incorporated in food products under different physicochemical structures, such as oil-in-water emulsions like cream or dressings, water-in-oil emulsions like butter or margarines, free oil or dispersed fat inclusions in cheeses or cookies. Among the various supramolecular structures, emulsified state is the most common and is getting a growing research interest regarding lipid digestion and absorption. Recent studies have revealed that molecular and supramolecular structures of dietary lipids can influence both their digestibility and the subsequent metabolism of fatty acids (FA) (Garaiova et al. 2007; Keogh et al. 2011; Vors et al. 2013; Michalski et al. 2013). In both in vitro and in vivo studies on fat digestion, it is therefore very important that the physical chemical properties of dietary fat are well defined and characterized to further assess their impact of digestion and absorption rates. Nevertheless, some artifactual changes may occur based on the methods and techniques used for monitoring lipid digestion. For instance, in clinical studies, the gold-standard method is to use ${ }^{13} \mathrm{C}$-labeled TAGs as tracers of the ingested fat to precisely track its metabolic fate (Binnert et al. 1998; Gabert et al. 2011; Heath et al. 2003; Vors et al. 2013; Lambert \& Parks 2012). We hypothesized that when such tracers contain saturated FA, their addition could modify the physicochemical properties of the fat, especially if these tracers are added in a high amount. Indeed, the crystallization, melting behavior and polymorphic stability of fats are determined by the behavior of the TAGs they contain. TAG molecules exhibit moreover a monotropic polymorphism, which notably complicates the thermal behavior of their mixtures. The structure of a fat in its solid state is thus function of its composition and of the temperature applied during processing and conditioning treatments. Milk fat is one of the most complex fats due to its wide diversity of FA and TAG molecules: more than 400 different FA were reported according to Jensen et al. 1991 and more than 200 TAG species according to Gresti et al. 1993. The crystallization and thermal 
behaviors of this particular fat are thus complex; they have however been widely studied and reported (Bugeat et al. 2015; Danthine 2012; Lopez et al. 2001; Ten Grotenhuis et al. 1999; Tzompa-Sosa et al. 2016).

Because ${ }^{13} \mathrm{C}$-TAG tracers are mostly available as homogeneous TAGs in terms of FA composition, a mixture of different types of ${ }^{13} \mathrm{C}$-TAGs with distinct FAs is the best choice to trace the complex metabolization of milk fat. The present study was conducted in the framework of a clinical trial (LIPINFLOX trial) dedicated to the effects of the physical structure (emulsion or bulk) of milk fat on lipid absorption, chylomicron transport and further metabolic handling of dietary fatty acids (Gabert et al. 2011; Vors et al. 2013). The homogeneous TAG tracers here were thus the same mixture of tripalmitin (PPP), triolein (OOO) and tricaprylin (CCC) like used in the LIPINFLOX trial. Tracers were added in the test fat (AMF) at 2 different concentrations of 1.5 and $5.7 \mathrm{wt} \%$ like in the different test meals of the LIPINFLOX trial.

To test whether tracer inclusion could change milk fat crystalline properties at body temperature, the thermal and polymorphic behavior of anhydrous milk fat (AMF) enriched with a mixture of external homogeneous TAGs as tracers were monitored using differential scanning calorimetry (DSC) and powder Xray diffraction (XRD) and compared to the native AMF. To reach our goal, we developed a special thermal kinetic approach in order to mimick the temperature gradient undergone by food products from the fridge to the stomach. We further tested whether the addition of tracers in AMF could modify its digestion rate in vitro.

\section{Experimental procedures}

\subsection{Materials}

The test fat was AMF supplied by CORMAN S.A. (Goé; Belgium); it was used as received. The skimmed milk was provided as powder by Lactalis R\&D (Retiers; France), and prepared and processed as bottled flavoured skimmed milk by Sodiaal-Candia R\&D (La Talaudière; France). Pure triacylglycerols (tripalmitin, triolein and trioctanoin) were from Sigma (respectively T5888, T7140 and T9126). As explained above, they were chosen to represent the three major FA classes in milk fat: medium-chain saturated, long-chain saturated and unsaturated FA. 


\subsubsection{Traced test fat preparation}

Anhydrous milk fat was first heated to $75{ }^{\circ} \mathrm{C}$ for at least 15 minutes to ensure complete melting. The pure TAGs were added to the AMF proportionally of each type of FA present in the test fat (Vors et al. 2013). Hence a mixture of $300 \mathrm{mg}$ of PPP, $210 \mathrm{mg}$ of $\mathrm{OOO}$ and $90 \mathrm{mg}$ of CCC, was added to $40 \mathrm{~g}$ of AMF (1.5 $\mathrm{wt} \%$ ) or to $10 \mathrm{~g}$ of AMF (5.7 wt $\%$ ). These proportions correspond to those that were considered in the LIPINFLOX clinical trial (Vors et al. 2013; Vors et al. 2015). The blends were then again further heated and mixed to ensure a good homogeneity.

\subsubsection{Emulsified fat preparation:}

Emulsions were prepared as follows: $40 \mathrm{~g}$ of anhydrous milk fat (enriched in TAGs, $1.5 \mathrm{wt} \%$, or not according to Vors et al., 2013) were first completely melted, thus preventing the existence of any remaining fat crystals; $160 \mathrm{ml}$ of skimmed milk were pre-heated to $37^{\circ} \mathrm{C}$ then added to the melted AMF. This blend was further mixed by shearing with an Ultra-Turrax T-45 laboratory homogenizer (IKA, Staufen, Germany) at $10000 \mathrm{rpm}$, for 4 minutes. After this step, the emulsions were refined using sonication (sonication $20 \mathrm{kHz}$; $400 \mathrm{~W}$ ), ultrasounds were applied as follows: sonication during $1 \mathrm{~min}$ followed by $1 \mathrm{~min}$ of rest, repeated 4 times. All emulsions were immediately analyzed or placed at $4 \pm 0.5^{\circ} \mathrm{C}$ overnight before other analysis.

\subsection{Particle size distribution by laser light scattering}

The fat droplets size distribution was assessed using a Malvern Mastersizer 2000 (Malvern Instruments, Malvern, UK), coupled with the liquid measurement cell (Hydro 2000S, Malvern Instruments, Malvern, UK). The measurements were conducted at room temperature as described by Anihouvi et al. (2013).

\subsection{Thermal analysis by Differential Scanning Calorimetry (DSC)}

DSC cooling and melting curves were recorded using a TA Q1000 DSC (TA Instruments, New Castle, DE, USA) coupled with a refrigerated cooling system (TA Instruments, New Castle, DE, USA), and aluminum hermetic pans. DSC was calibrated with indium (m.p. $156.6{ }^{\circ} \mathrm{C}$ ), eicosane (m.p. $36.8{ }^{\circ} \mathrm{C}$ ) and n-dodecane (m.p. $-9.65{ }^{\circ} \mathrm{C}$ ) standards before analysis. Nitrogen was used to purge the system to prevent condensation. 
An empty pan was used as reference. Samples weighed between 2 and $4 \mathrm{mg}$. The integration and peaks temperature determinations were performed as shown in Figure 1, using the Universal Analysis Software version 4.2 (TA Instruments, New Castle, USA). The melting peaks were integrated using a linear baseline (Figure 1). All the DSC analyses were carried out in triplicate. Thermal profiles were recorded according to different procedures as described hereafter.

Two sets of conditions were considered:

A) "Dynamic conditions": the AOCS Cj1-94 official method (cooling rate $-10{ }^{\circ} \mathrm{C} / \mathrm{min}$; heating rate 5 ${ }^{\circ} \mathrm{C} / \mathrm{min}$ ) was first used, it was then slightly modified: cooling rate $-10^{\circ} \mathrm{C} / \mathrm{min}$; heating rate $15^{\circ} \mathrm{C} / \mathrm{min}$.

B) Protocols especially set up in order to mimic the real conditions of product preparation and consumption, as in the clinical trials. To this end, the actual thermal profile of the real products (bulk fats and emulsions) during their production and ingestion was first determined. Based on that actual profile (see Figure 2), samples were first heated in the DSC pan to $80^{\circ} \mathrm{C}$ to ensure a complete melting and held for 5 min at that temperature to erase thermal memory effects. Afterwards, they were cooled down to $4^{\circ} \mathrm{C}$ using a cooling rate of $-1.00^{\circ} \mathrm{C} / \mathrm{min}$. They were further kept 15 hours at $4^{\circ} \mathrm{C}$ (same as one night in the fridge).

Afterwards, two set of experiments were conducted:

1) The melting curves were recorded from $4^{\circ} \mathrm{C}$ to $70^{\circ} \mathrm{C}$ using a heating rate of $15^{\circ} \mathrm{C} / \mathrm{min}$.

2) In the second procedure, the melting curves were recorded using a heating rate of $15^{\circ} \mathrm{C} / \mathrm{min}$, from $4^{\circ} \mathrm{C}$ to $37.0^{\circ} \mathrm{C}$. Afterwards, the samples were kept in the DSC at $37^{\circ} \mathrm{C}$ for an isothermal period of 4 hours. This step was set to mimic fat being at body temperature during digestion. After this isothermal period, the samples were further reheated from $37^{\circ} \mathrm{C}$ to $70{ }^{\circ} \mathrm{C}$ at the same heating rate $\left(15^{\circ} \mathrm{C} / \mathrm{min}\right)$; the corresponding thermograms were recorded. 


\subsection{Polymorphic behavior by X-Ray Diffraction}

Short spacings were measured by XRD using a Bruker D8 Advance Diffractometer (Bruker, Germany) with

$\mathrm{Cu} \mathrm{K} \alpha$ radiation $(\lambda=1.5418 \AA$, $40 \mathrm{kV}, 30 \mathrm{~mA})$ equipped with an Anton Paar temperature control system composed of a TTK450 low temperature chamber and a heating device (TCU 110 Temperature Control Unit, Anton Paar, Graz, Austria) coupled with a water bath (Lauda, Germany). Investigations were conducted on bulk and emulsions using a VANTEC-1 detector (Bruker, Germany). The samples were scanned from $15^{\circ}$ to $27^{\circ} 2 \theta$, thus covering the wide-angle region. The measurement time was $30 \mathrm{sec}$ (snap-shot mode), with a step size of $0.016^{\circ}$. The wide-angles were converted into d-spacings values using the Bragg law: $n \lambda=2 \mathrm{~d}$ $\operatorname{Sin} \theta$. Each condition was run at least in duplicate for each sample according to the best practices in the field.

The temperature program used for the polymorphic investigations was the same as for DSC (§2.2.2. B-b). The whole process can be divided into four main parts corresponding to the real profile described in Figure 2:

1. "Food preparation": Heating of the fat at $80^{\circ} \mathrm{C}$ (with an isotherm for 5 minutes) followed by a cooling at $-1.00^{\circ} \mathrm{C} / \mathrm{min}$.

2. "One night in the fridge": Isothermal period of 15 hours at $4^{\circ} \mathrm{C}$.

3. "Food ingestion": Heating from $4^{\circ} \mathrm{C}$ to $37^{\circ} \mathrm{C}$ (estimated heating rate of $15^{\circ} \mathrm{C} / \mathrm{min}$.)

4. "Food digestion": Isothermal period of 4 hours at $37^{\circ} \mathrm{C}$.

Frames were recorded continuously during the 4 periods. They were analyzed using the DIFFRAC.EVA (V.3.0, Bruker, Germany) software.

\subsection{In vitro digestion by pancreatic lipase}

2.5.1. AMF Preparation and in vitro simulation of intestinal lipolysis

Bulk fat consisted in anhydrous milk fat enriched or not with 1.5 or $5.7 \mathrm{wt} \%$ of PPP, OOO and CCC as described above and stored at $4^{\circ} \mathrm{C}$ (see 2.1.1). The day before each digestion assay, thermal history of test 
fats was reset by complete melting at $75^{\circ} \mathrm{C}$, and fat was stored at $4{ }^{\circ} \mathrm{C}$ overnight to mimic the procedure of clinical trials and of X-ray/DSC experiments.

In vitro digestion assays simulating intestinal lipolysis were performed using the $\mathrm{pH}$-stat technique, at a constant $\mathrm{pH}$ of 6.25 taken as the mean $\mathrm{pH}$ of duodenal contents during meal digestion (Carrière et al. 2000), followed by back-titration at $\mathrm{pH}$ 9. The free fatty acids (FFA) released during lipolysis at $37^{\circ} \mathrm{C}$ were titrated with $0.1 \mathrm{~N} \mathrm{NaOH}$ delivered by a Mettler Toledo $\mathrm{T} 70 \mathrm{pH}$-stat. In the reaction vessel, equipped with the $\mathrm{pH}$ electrode and mechanical stirring, $200 \mathrm{mg}$ of AMF were first homogenized in $15 \mathrm{~mL}$ of $150 \mathrm{mM} \mathrm{NaCl}, 1.4$ $\mathrm{mM} \mathrm{CaCl} 2$, during 20 minutes $\left(37^{\circ} \mathrm{C}, \mathrm{pH}=6.25\right)$. Then $8 \mathrm{~mL}$ of $10 \mathrm{mM}$ sodium taurodeoxycholate (NaTDC) solution were added to ensure emulsification of AMF. The lipolysis reaction was launched by adding $3 \mathrm{~mL}$ of porcine pancreatic extracts (PPE; Pancreatin Sigma P7545; $8 \times$ USP specifications) solution at $27.9 \mathrm{mg} / \mathrm{mL}$ in $10 \mathrm{mM} \mathrm{NaTDC} 10 \mathrm{mM}$ ) and was monitored during $60 \mathrm{~min}$. Finally, back-titration at $\mathrm{pH} 9$ allowed to fully titrate all FFA released during the reaction. A blank assay without PPE was performed in order to estimate the $\mathrm{NaOH}$ volume required to change the $\mathrm{pH}$ from 6.25 to 9 , and this volume was subtracted from the volume measured in the presence of PPE to determine the volume of $\mathrm{NaOH}$ corresponding to FFA titration. A correction factor for the partial ionization of the FFA at $\mathrm{pH} 6.25$ was then establish from the ratio of the full titration to the apparent titration at $\mathrm{pH} 6.25$, in order to estimate the effective rate of FFA release as a function of time (Chatzidaki et al. 2016). Before each assay, the lipase activity of PPE solution was controlled using tributyrin as substrate as recommended in Minekus et al. (2014).

Twenty-one digestion assays ( 8 for AMF without tracers, 7 for AMF with $1.5 \%$ tracers and 6 for AMF with $5.7 \%$ tracers) were performed without sample collection, allowing for the most precise measurement of released FFA. Four additional assays ( 2 without tracers and 2 with 5.7\% tracers) were performed with collection of $1 \mathrm{ml}$ samples at $\mathrm{t}=0,10,20,30,40,50,60 \mathrm{~min}$ for further biochemical analysis (see section 2.5.2 below), allowing for a quantification of intermediary lipolysis products. 
2.5.2. Lipid extraction and TLC-FID analysis of TAG lipolysis products

Lipid extraction was performed immediately after sampling according to Folch et al. procedure (1957). One $\mathrm{ml}$ of reaction mixture was mixed with $200 \mu \mathrm{l} 0.1 \mathrm{~N} \mathrm{HCl}$ and $5 \mathrm{ml}$ chloroform/methanol (2:1, v/v) using vortex in a $15-\mathrm{mL}$ glass tube. After phase separation, the lower organic phase was totally collected and transferred in a new glass tube, dried on anhydrous magnesium sulfate, filtered and stored à $-20^{\circ} \mathrm{C}$ before lipid analysis. The quantitative analysis of residual TAG and lipolysis products (FFA, diacylglycerols (DAG) and monoacylglycerols (MAG)) was performed by thin-layer chromatography coupled to flame ionization detection (TLC-FID technique) using a Iatroscan MK6 equipment (Iatron Laboratories) (Cavalier et al. 2009). Briefly, $1 \mu \mathrm{l}$ of each lipid extract was spotted onto a quartz rod coated with silica $(0.9 \mathrm{~mm}$ diameter Chromarod $^{\mathrm{TM}}$ SIII, Iatron Laboratories) and sample migration was performed with heptane/ether/formic acid $(55: 45: 1 \mathrm{v} / \mathrm{v} / \mathrm{v})$. Chromarods were dried at $150^{\circ} \mathrm{C}$ for $15 \mathrm{~min}$ in a Rod dryer TK8 (Iatron Laboratories) and transferred to the Iatroscan MK6 to be scanned by the FID for detection and quantification of the compounds separated on silica.

Peaks were integrated with the Chromstar software and converted to TAG, DAG and MAG masses, based on calibration curves obtained with triolein, 1,2-diolein and 1-monoolein, respectively. The masses were then converted to moles using average molar masses of $786.4 \mathrm{~g} / \mathrm{mol}, 554.9 \mathrm{~g} / \mathrm{mol}$ and $323.5 \mathrm{~g} / \mathrm{mol}$ for TAG, DAG and MAG, respectively, estimated from the fatty acid composition of AMF. Although FFA could be seen on TLC-FID chomatograms, the levels could not be precisely quantified because (i) the short- to medium-chain fatty acids of AMF are not completely extracted and (ii) their detection by FID is not equivalent to the detection of the oleic acid standard. Therefore, FFA levels were estimated from the other molecular species, assuming that $1 \mathrm{DAG}$ corresponds to the release of $1 \mathrm{FFA}$ and $1 \mathrm{MAG}$ to the release of $2 \mathrm{FFA}$, and that MAG were not converted to glycerol in our experimental conditions $\left(n_{\mathrm{FFA}}=2 n_{\mathrm{MAG}}+n_{\mathrm{DAG}}\right)$. This could be checked by comparing the sum of TAG, DAG and MAG moles at a given time compared to the initial moles of TAG. The hydrolysis rate was then computed as $\mathrm{H}=n_{\mathrm{FFA}} /\left(3 n_{\mathrm{TAG}}+2 n_{\mathrm{DAG}}+n_{\mathrm{MAG}}+n_{\mathrm{FFA}}\right)$. This rate corresponds to the fraction of acyl chains that are not esterified anymore. 


\subsubsection{Statistical analyses}

All lipolysis data are presented as means \pm s.e.m. and were analyzed with softwares R 3.5.1 and Rstudio 1.1.463. The kinetics of FFA release was first analyzed globally with a mixed-design ANOVA, where the response was the corrected concentration of FFA, the within-assay factor was time and the between-assays factor was the tracer concentration. The purpose of such an analysis is to test whether there is an interaction between those two factors. Formally, this mixed-design ANOVA is equivalent to modeling the concentration of fatty acids $y_{i j k}$ at time $i$ for assay $k$ of tracer concentration $j$ as a linear mixed-effects model: $y_{i j k}=\mu+t_{i}+c_{j}+\gamma_{i j}+a_{k^{j}}+\epsilon_{i j k}$, where $\mu$ is a general intercept, $t_{i}$ is the shift associated with time $i$, $c_{j}$ is the shift associated with tracer concentration $i, \gamma_{i j}$ is the shift associated with both time $i$ and tracer concentration $i$ (interaction term), $a_{k^{j}} \sim \mathcal{N}\left(0, \sigma_{\text {assay }}^{2}\right)$ is the random effect associated to assay $k^{j}$, and $\epsilon_{i j k} \sim \mathcal{N}\left(0, \sigma^{2}\right)$ is the residual. This linear mixed-effect model was fitted with the "lme" function of the "nlme" package, using treatment contrasts. F-tests for the factors and their interaction were computed using type I (sequential) sums of squares, with the following term order: time, tracer concentration, interaction between both. F-values with $\mathrm{p}<0.05$ were considered significant. To get more insight, $\mathrm{z}$-tests were performed for the fixed-effect model coefficients (i.e. for $\mu$, for the $60 t_{i}$, for the two $c_{j}$ and for the $120 \gamma_{i j}$ ), to determine which ones were significantly different from zero. This amounts to a total of 183 z-tests. To correct for multiple testing, a Bonferroni-corrected significance threshold of $0.05 / 183 \approx 0.00027$ was used for those z-tests.

Additionally, to further characterize the lipolysis kinetics, two summary indicators were computed for each assay: (a) the maximal rate of lipolysis ( $\mu$ mole FFA released per min), computed as the slope of the steepest tangent to the curve and (b) the lag time, defined as the intersection of this tangent with the $\mathrm{x}$-axis. For each indicator, a one-way ANOVA was performed to assess the effect of tracer concentration. An F-value with $\mathrm{p}<0.05$ was considered significant, in which case Tukey's post-hoc multiple comparisons test was performed to compare the mean differences. The mean differences with $p<0.05$ were considered significant. 


\section{Results and Discussion}

\subsection{Bulk fat thermal and crystalline behavior according to the incorporation of homogeneous TAG}

\subsubsection{DSC melting profiles}

\section{Preliminary tests:}

The crystallization and melting curves of the bulk fat (enriched or not) were first investigated using the AOCS official method. During non-isothermal crystallization (Figure 3-A) two main peaks were observed. The onset temperature indicating the start of the crystallization process was influenced by the presence of tracers and their concentration. Indeed, $16^{\circ} \mathrm{C}$ was observed for native $\mathrm{AMF}$ (curve 1), while $16^{\circ} \mathrm{C}$ and $19^{\circ} \mathrm{C}$ were observed after addition of 1.5 and $5.7 \%$ of TAG tracers respectively (curve 2 and 3). The main crystallization peak was observed at $8^{\circ} \mathrm{C}$ in all cases $\left(\mathrm{T}^{\circ}\right.$ peak max). However the relative percentage of the two peaks was modified upon TAG tracers addition: $\mathrm{p} 2: 93 \%-\mathrm{p} 1: 7 \%, \mathrm{p} 2: 91 \%-\mathrm{p} 1: 9 \%$ and $\mathrm{p} 2: 86 \%-\mathrm{p} 1: 14 \%$ for the native AMF, after addition of 1.5 and $5.7 \%$ of external TAG tracers respectively. The melting curve of native AMF (Figure 3-B, curve 1) obtained after non-isothermal crystallization (cooling rate $-10^{\circ} \mathrm{C} / \mathrm{min}$ ) can be divided into three main endothermic regions (see Figure 1) according to their melting range (p1, p2, p3) in accordance to literature data (Danthine, 2012). Under those dynamic conditions (without any particular temperature profile), the enrichment of AMF in the low concentration has nearly no impact on its melting properties. Only a small shoulder could be observed in the medium melting peak (p2) in the melting profile of the enriched AMF (Figure 3-B, curve 2), all the maximum peak temperatures are similar (Figure 3-B, curves $1 \& 2$ ). Both native AMF and AMF enriched in the low tracer concentration (1.5\%) were completely melted at around $37^{\circ} \mathrm{C}$, i.e. close to the body temperature. An addition of a higher concentration of tracers (5.7\%) had however a higher impact on the AMF melting profile. Indeed, a broadening was observed for the medium melting peak (p2) and both peak temperatures of the medium melting peak (p2) and the high melting peak (p3) were shifted to higher values upon 5.7\% tracers addition. Moreover, AMF enriched in the high tracers concentration remained partially solid at $37^{\circ} \mathrm{C}$ (Figure 3-B, curve 3). 
As the actual temperature gradient observed in the real thermal profile underwent by the dietary fat during its preparation and consumption was estimated at $15^{\circ} \mathrm{C} / \mathrm{min}$ (see Figure 2) and not $5^{\circ} \mathrm{C} / \mathrm{min}$ as in the reference method, the melting curves of the three investigated samples were also recorded using the same heating rate $\left(15^{\circ} \mathrm{C} / \mathrm{min}\right)$ (Figure $\left.4-\mathrm{B}\right)$. Trends were similar to those observed at $5^{\circ} \mathrm{C} / \mathrm{min}$ : the small concentration $(1.5 \%)$ had a limited impact (mainly observed in the medium melting region), while the high concentration (5.7\%) modified the ratio between the high melting peak and the (low+medium) melting peaks. The most important modification due to the addition of $5.7 \%$ of the investigated TAGs was again a shift of the final melting temperature to a higher value, which was moreover higher than the body temperature (Figure 4-B, curve 3). This validates our initial hypothesis and prompted us to test impact on digestive lipolysis in vitro.

Physical state variations with temperature changes mimicking the post-ingestion phase of dietary fat:

In order to better highlight and understand the behavior of the fats when ingested, a procedure aiming at mimicking the real conditions of the clinical trials (Figure 2) was set. It was used to monitor the thermal and polymorphic behavior of anhydrous milk fat (AMF) enriched or not in tracers.

The first part of the method was designed to get information regarding the physical state of the fat after the storage in the fridge (one night at $4^{\circ} \mathrm{C}$ ), just before its ingestion. DSC results are presented in Figure 5-A (crystallization curves) and B (melting curves). After the slow cooling at $-1{ }^{\circ} \mathrm{C} / \mathrm{min}$ (crystallization curves, Figure 5-A), followed by $15 \mathrm{~h}$ at $4^{\circ} \mathrm{C}$, the first melting peak observed at $21^{\circ} \mathrm{C}$ (melting curves Figure 5-B) is similar whatever the fat, AMF enriched or not. However, a significant difference was observed for the higher melting peak. AMF and AMF enriched with $1.5 \%$ of tracer present similar melting curves while this higher melting peak is broader and shifted to higher temperatures for the AMF enriched with $5.7 \%$ of tracers (Figure 5-B, curve 3). A zoom presenting an overlapping of the three curves is also made in Figure 5-B to better highlight the phenomenon. Again, this high enrichment lead to a modification in the crystallization behavior (Figure 5-A) of the AMF sample, which, during the reheating at $15^{\circ} \mathrm{C} / \mathrm{min}$, remained partially solid at body temperature $\left(37^{\circ} \mathrm{C}\right)$ as shown on Figure 5-B (zoom); the partial melting enthalpy from $37^{\circ} \mathrm{C}$ to the end of melting represents in this case $8 \%$ of the total melting enthalpy, this should be compared to around $1 \%$ for the native AMF. 
The second part of the method was set to get information regarding the behavior of the fats upon ingestion and digestion. The modifications due to the addition of TAG tracers were even strengthened during the isothermal period of 4 hours at $37^{\circ} \mathrm{C}$, as indicated by the DSC melting curves presented in Figure 6-A. The melting curve from $37^{\circ} \mathrm{C}$ to $70^{\circ} \mathrm{C}$ obtained for the native AMF or with $1.5 \%$ of TAGs is flat indicating that no solid are present above $37^{\circ} \mathrm{C}$. On the contrary, the signal is not flat when $5.7 \%$ of TAGs were added, indicating that a part of the fat is melting beyond $37^{\circ} \mathrm{C}$ (and thus was solid above $37^{\circ} \mathrm{C}$ ). To better highlight this point, Figure 6-B represents a comparison between the DSC melting curves obtained with and without the isothermal period (zoom on the $25-65^{\circ} \mathrm{C}$ range). It is obvious that the isothermal step of 4 hours at $37^{\circ} \mathrm{C}$ has a huge impact in the case of AMF containing 5.7\% of tracers: the percentage of solids is almost doubled after the $4 \mathrm{~h}$ at $37^{\circ} \mathrm{C}$ and the end of melting is even shifted to higher temperature (peak max $42^{\circ} \mathrm{C}$ instead of $\left.38^{\circ} \mathrm{C}\right)$.

\subsubsection{Polymorphic behavior by XRD}

During their crystallization, fats (TAGs) pack into characteristic crystal polymorphs. The packing depends on several parameters such as cooling rate, temperature, amount of liquid oil and, of course, the TAG composition of the fat. In milk fat, the types of polymorphic forms that can be found are $\alpha, \beta$ ' and $\beta$. As for other fats, those polymorphic forms are characterized by specific d-spacings values using wide-angle X-ray diffraction: $4.15 \AA$; 4.2 and $3.8 \AA$; $4.6 \AA$ (and others minors) for $\alpha, \beta$ ' and $\beta$ respectively (Tzompa-Sosa et al, 2016).

In order to better understand the impact of tracers on AMF crystallization, the polymorphic behavior of the three samples was investigated by powder X-ray diffraction under the thermal conditions aiming at mimicking the real temperature profile already as in Figure 2.

The first part of this specific temperature profile corresponded to the slow cooling $\left(-1^{\circ} \mathrm{C} / \mathrm{min}\right)$ from $80^{\circ} \mathrm{C}$ to $4^{\circ} \mathrm{C}$. During this slow cooling, the liquid fat samples crystallized first into the $\alpha$-form. At the end of the cooling, when $4^{\circ} \mathrm{C}$ was reached, both $\mathrm{AMF}$ and $\mathrm{AMF}$ containing $1.5 \%$ of tracers were still mainly crystallized under the $\alpha$-form (Figure 7-A). On the contrary, the sample enriched with 5.7\% of external TAG 
tracers quickly crystallized under the $\beta$ '-form, indicating that the kinetic of crystallization and polymorphic transformation is impacted by the amount of added tracers (Figure 7-A).

During the second part of the temperature profile, corresponding to the isothermal period mimicking the overnight storage in a fridge $\left(15\right.$ hours at $\left.4^{\circ} \mathrm{C}\right)$, all the samples evolved into more stable polymorphic forms. The last frames collected at the end of this isothermal period are presented in Figure 7b: both native AMF and AMF enriched with $1.5 \%$ of external TAG tracers evolved from the $\alpha$-form to the $\beta$ ' form. The AMF enriched with $5.7 \%$ of tracers that was already crystallized under the $\beta$ '-form when it reach $4^{\circ} \mathrm{C}$ continued to evolve during this isothermal period. The resulting crystalline state was in this case a mixture of $\beta$ ' and $\beta$ forms, as indicated by the characteristic peak of the $\beta$-form observed at a d-value of $4.6 \AA$ (see arrow on Figure 7-B).

The third part of the temperature profile corresponded to a heating from $4{ }^{\circ} \mathrm{C}$ to $37{ }^{\circ} \mathrm{C}$ at $15{ }^{\circ} \mathrm{C} / \mathrm{min}$ (as in the DSC experiments). The XRD frames collected during this period are presented as a function of temperature in Figure 7-C. Native AMF (Figure 7- $\mathrm{C}_{1}$ ) and AMF enriched with $1.5 \%$ of tracers (Figure 7-C ${ }_{2}$ ) completely melted below $37{ }^{\circ} \mathrm{C}$ (no peak detected at $37^{\circ} \mathrm{C}$ ), while AMF containing 5.7\% remained partially crystallized beyond $37{ }^{\circ} \mathrm{C}$ (Figure 7- $\mathrm{C}_{3}$ ), in accordance with the DSC results (see Figure 5). At this temperature, AMF enriched with $5.7 \%$ of tracers is made of a blend of liquid fat and a very small amount of $\beta$-form crystals (see arrows on Figure $7-\mathrm{C}_{3}$ ).

The fourth period corresponded to the isotherm of 4 hours at $37^{\circ} \mathrm{C}$ (representing the digestion itself), XRD frames obtained at the end of this period are presented in Figure 7-D. Both native AMF and AMF enriched with $1.5 \%$ remained completely liquid (no peak were detected). On the contrary, the sample that contained $5.7 \%$ of tracers remained crystallized (curve 3) and it was even observed that the amount of crystals increased during this isothermal period, which is consistent with DSC data. The peaks corresponding to the $\beta$ form are becoming more intense and better resolved most probably linked to recrystallizations occurring due to the higher amount of PPP present in this enriched AMF sample (Figure 7-E). 


\subsection{Thermal and structural behavior of emulsion upon incorporation of homogeneous TAG tracers}

In view of the results obtained for the bulk fats, indicating that $5.7 \%$ concentration should be avoided, only the effect of the $1.5 \%$ concentration was investigated in emulsions. Of note, the emulsion consumed by the subjects of the Lipinflox clinical trial was enriched only with this low concentration of tracers (Vors et al. 2013).

\subsubsection{Particle size distribution}

It is well known that fat emulsification can modify the nucleation kinetics and further the physical properties of the fat. The droplets size and distribution are factors that can affect the nucleation mechanism (Truong et al. 2014). For this reason, the particles size distribution was first assessed by laser light scattering. Measurements were performed just after recombination and also after 15 hours of storage at $4^{\circ} \mathrm{C}$. Results are presented in Figure 8. Both emulsions formulated with AMF or AMF enriched with $1.5 \%$ of tracers presented the same distribution, and this both after recombination and after 15 hours of maturation at $4^{\circ} \mathrm{C}$. As similar particles sizes and distribution were observed in both systems, they should undergo similar crystallization mechanism (Petrut et al. 2016).

\subsubsection{DSC melting curves}

The DSC melting profiles recorded from $4{ }^{\circ} \mathrm{C}$ to $70^{\circ} \mathrm{C}$ of the emulsions prepared with AMF or AMF enriched with $1.5 \%$ of tracers are presented in Figure 9. As in the case of the bulk fats, the addition of $1.5 \%$ tracers did not impact the melting profile of the emulsion, which is good for studies such as clinical trials.

\subsubsection{Polymorphic behavior by XRD}

Regarding polymorphism, again, similar crystal types were found in both systems after the night spent at 4 ${ }^{\circ} \mathrm{C}$; after heating up to $37{ }^{\circ} \mathrm{C}$, no remaining crystals could be detected (data not shown), indicating that the fat is completely melted in both cases.

Similar trends were observed in both bulk fat and emulsions, using the low concentration of TAG tracers, 
indicating that this concentration could be used for clinical studies without having a significant impact on the physical state of the AMF both in bulk and emulsions.

\subsection{Impact of tracing AMF with homogeneous $\mathrm{TAG}$ on digestion by pancreatic lipase in vitro}

To verify whether the presence of TAG tracers could impact the digestion of AMF, we performed an in vitro digestion study under conditions mimicking gastrointestinal lipolysis by pancreatic lipase in the small intestine. Figure 10A shows the evolution of the release of free fatty acids as a function of time for native AMF and AMF enriched with $1.5 \%$ and $5.7 \%$ of TAG tracers. While the rate of FFA released from AMF was not changed by the low concentration of TAG tracers, a highly significant interaction effect $\left(\mathrm{F}_{120,1080}=\right.$ 2.518; $\mathrm{p}=6.9410^{-15}$ ) was observed with $5.7 \%$ of TAG tracers in the 4 to 40 -min time range and the difference with the assays performed with native AMF without TAG tracers was significant $(\mathrm{p}<0.01$; mixed ANOVA coefficient z-tests). Taking into account that 183 z-tests were performed (see methods), the Bonferroni correction indicates a significant difference of $5.7 \%$ tracers $v s$ control between $\mathrm{t}=5$ and $\mathrm{t}=12$ minutes $\left(p<0.05 / 183\right.$, i.e. $p<2.7 .10^{-4}$ ), which was even highly significant between $t=6$ and $t=11$ minutes $\left(\mathrm{p}<0.001 / 183\right.$, i.e. $\left.\mathrm{p}<5.4 \cdot 10^{-6}\right)$. Analyzing the tangent with the steepest slope for each assay reveals that $5.7 \%$ tracer concentration does not impact the maximum rate of lipolysis $(1.32 \mu \mathrm{mol} \mathrm{FFA} / \mathrm{mL} / \mathrm{min}$ without tracers, $1.41 \pm 0.07 \mu \mathrm{mol} \mathrm{FFA} / \mathrm{mL} / \mathrm{min}$ with $1.5 \%$ tracers, $1.21 \pm 0.04 \mu \mathrm{mol} \mathrm{FFA} / \mathrm{mL} / \mathrm{min}$ with $5.7 \%$ tracers ; oneway ANOVA, $\mathrm{F}_{2,18}=1.887, \mathrm{p}=0.18$ ), but delays significantly its initiation. The lag time for reaching maximum rate of lipolysis are shown on figure $10 \mathrm{~B}$, one-way ANOVA, $\mathrm{F}_{2,18}=15.937, \mathrm{p}=0.0001$ ). Kinetics of FFA release recorded in the presence of 5.7\% TAG tracers showed a 2-fold longer lag time compared to kinetics recorded with native AMF (Tukey's posthoc test, $p=0.0002$ ). Given that the AMF enriched with $5.7 \%$ of tracers remained partially crystallized at $37^{\circ} \mathrm{C}$ as demonstrated above, one can hypothesize that this could hamper the initial interaction of pancreatic lipase with the lipid substrate. On the opposite, AMF enriched with only $1.5 \%$ of TAG tracers had similar lipolysis kinetics as regular AMF, which is consistent with the fact that both were completely melted at around $37{ }^{\circ} \mathrm{C}$, i.e. close to the body temperature. Altogether, these results suggest that using $1.5 \%$ of TAG tracers in fats used in clinical trials is much less likely to alter the digestive physiology of the traced fat than using $5.7 \%$ of tracers. 
To further explore the mechanism of 5.7\% TAG tracer impact on lipolysis, we analyzed the remaining triacylglycerols (TAG) and lipolysis products, i.e., diacylglycerols (DAG), monoacylglycerols (MAG) and free fatty acids (FFA) in the course of the reaction, for both native AMF and AMF with 5.7\% TAG tracers. Consistently with the $\mathrm{pH}$-stat measurements, FFA release estimated from lipolysis product analysis was lower along digestion of AMF enriched with tracers $5.7 \%$ (see the inset in Figure 10A). In parallel accordingly, TAG disappearance was also slower. Regarding intermediate lipolysis products, DAG accumulation was slightly higher while MAG accumulation was lower with 5.7\% tracers. Figure 10C shows however that lipolysis product variations are identical when they are plotted as a function of the hydrolysis rate. This type of representation reflects the substrate specificity of the lipase involved (Michell et al. 2008). One can observe here a transient production of DAG followed by MAG accumulation, which reflects the 1,3-regiospecificity of pancreatic lipase and the fact that 2-MAG resulting from lipolysis is not a substrate for the lipase. The absence of difference between AMF and AMF enriched with 5.7\% TAG tracers indicates that the relative rates of TAG and DAG hydrolysis by pancreatic lipase and its specificity are not affected by the tracers. One can thus speculate that the tracers do not have a direct impact on the reactions occurring at the interface but they might rather impact the adsorption of the lipase onto its TAG substrate, in line with the longer lag times observed in the presence of tracers.

Altogether, these results confirm that crystalline behavior of AMF enriched with high concentration (5.7\%) of tracers impacts pancreatic lipase activity by slowing down the initiation of lipolysis. AMF enriched with low concentration of tracers $1.5 \%$ presents similar behavior to regular AMF during digestion. Our findings are in line with previous studies showing that fat in which the endogenous TAG are in the solid state can influence the steps of lipid digestion and intestinal absorption (Berry et al. 2007). Fat with TAG species carrying FA with a high melting point $\left(>37^{\circ} \mathrm{C}\right.$, body temperature) are still partially solid in the digestive tract, which limits the action of lipolytic lipases (Berry \& Sanders 2005). Moreover, the in vitro digestion by pancreatic lipase of a pure tripalmitin emulsion containing solid lipid particles is lower than the same emulsion in a totally liquid form (Bonnaire et al. 2008). Similarly, the in vitro lipolysis of an emulsion of cocoa butter enriched or not with betacarotene was shown to be delayed when the emulsion is in the solid versus the liquid state, using a two-step digestion model with gastric and duodenal phases (Hart et al. Food 
Chem 2018). The novelty of the present results is to show that even a few percent of homogeneous TAG of high melting point within fat can also delay the onset of digestive lipolysis in vitro.

\section{Conclusions}

The addition of a mixture of homogeneous TAG tracers (PPP+OOO+CCC) modified the AMF melting profile at the highest tested concentration (5.7\%). Both AMF and AMF enriched with the low concentration of tracers $(1.5 \%)$ were completely melted at around $37^{\circ} \mathrm{C}$, i.e. close to the body temperature. Similar trends were observed in both systems (bulk vs emulsified). On the contrary, the AMF enriched in high tracer concentration $(5.7 \%)$ remained partially crystallized at $37{ }^{\circ} \mathrm{C}$. Moreover, AMF polymorphic behavior was modified upon tracer addition. The kinetic of polymorphic transformation was modified in the presence of tracers. While $\beta$ ' form was observed in the native AMF, the $\beta$-form was clearly detected in the AMF containing the highest TAGs concentration. This resulted in a delay in the onset of duodenal lipolysis in vitro, which will now deserve to be explored in vivo. Importantly, in view of all those results, low concentration of tracers $(1.5 \mathrm{wt} \%)$ should not impact human digestive physiology. However more attention should be paid to fat physicochemical structure when higher tracer concentrations are added, e.g., in postprandial metabolic tests using low amounts of dietary fat but similar amount of tracers for further detection purpose in biological samples.

\section{Acknowledgements}

The authors thank Sandrino Filocco for his technical assistance. Lean Dorann is acknowledged for revising English language. 


\section{References}

Anihouvi, P., Danthine, S., Kegelaers, Y., Dombree, A., Blecker, C., 2013. Comparison of the physicochemical behavior of model oil-in-water emulsions based on different lauric vegetal fats. Food Res. Int. 53, 156-163.

Berry, S.E., Miller, G.J., Sanders, T.A., 2007. The solid fat content of stearic acid-rich fats determines their postprandial effects. Am. J. Clin. Nutr., 85(6), 1486-1494.

Berry, S.E., Sanders, T.A., 2005. Influence of triacylglycerol structure of stearic acid-rich fats on postprandial lipaemia. Proc. Nutr. Soc. 64(2), 205-212.

Binnert, C., Pachiaudi, C., Beylot, M., Hans, D., Vandermander, J., Chantre, P., Riou, J.P., Laville, M., 1998. Influence of human obesity on the metabolic fate of dietary long- and medium-chain triacylglycerols. Am. J. Clin. Nutr. 67(4), 595-601.

Bonnaire, L., Sandra, S., Helgason, T., Decker, E.A., Weiss, J., McClements, D.J., 2008. Influence of lipid physical state on the in vitro digestibility of emulsified lipids. J. Agric. Food Chem. 56(10), 3791-3797.

Bugeat, S., Perez, J., Briard-Bion, V., Pradel, P., Ferlay, A., Bourgaux, C., Lopez C., 2015. Unsaturated fatty acid enriched vs. control milk triacylglycerols: Solid and liquid TAG phases examined by synchrotron radiation X-ray diffraction coupled with DSC. Food Res. Int. 67, 91-101.

Carrière, F., C. Renou, V. Lopez, J. De Caro, F. Ferrato, H. Lengsfeld, A. De Caro, R. Laugier, and R. Verger. 2000. The specific activities of human digestive lipases measured from the in vivo and in vitro lipolysis of test meals. Gastroenterology 119: 949-960.

Carrière F. and Grundy M., 2017. Round-robin tests of various lipase sources within the INFOGEST network. In: INFOGEST Network - WG4 Lipases and lipid digestion.

Cavalier JF, Lafont D, Boullanger P, Houisse D, Giallo J, Ballester JM, Carrière F., 2009. Validation of lipolysis product extraction from aqueous/biological samples, separation and quantification by thin-layer 
chromatography with flame ionization detection analysis using O-cholesteryl ethylene glycol as a new internal standard. J Chromatogr A. 1216(37):6543-8.

Chatzidaki, M. D., E. Mateos-Diaz, F. Leal-Calderon, A. Xenakis, and F. Carriere. 2016. Water-in-oil microemulsions versus emulsions as carriers of hydroxytyrosol: an in vitro gastrointestinal lipolysis study using the pHstat technique. Food Funct 7: 2258-2269.

Danthine, S., 2012. Physicochemical and structural properties of compound dairy fat blends. Food Res. Int. 48, 187-195.

Folch J., Lees M., Sloane Stanley G.H., 1957. A simple method for the isolation and purification of total lipids from animal tissues. J. Biol. Chem., 226(1), 497-509

Gabert, L., Vors, C., Louche-Pélissier, C., Sauvinet, V., Lambert-Porcheron, S., Drai, J., Laville, M., Désage, M., Michalski, MC., 2011. 13C tracer recovery in human stools after digestion of a fat-rich meal labelled with [1,1,1-13C3]tripalmitin and [1,1,1-13C3]triolein. Rapid Commun Mass Spectrom. 15; 25(19), 2697 2703. doi: 10.1002/rcm.5067. PMID: 21913246.

Garaiova, I., Guschina, I., Plummer, S., Tang, J., Wang, D., Plummer, N., 2007. A randomised cross-over trial in healthy adults indicating improved absorption of omega-3 fatty acids by pre-emulsification. Nutr. J. 6 (1), 4-.

Hart S.M., Lin X.L., Thilakarathna S.H., Wright A.J.2018. Emulsion droplet crystallinity attenuates early in vitro digestive lipolysis and beta-carotene bioaccessibility. Food Chem. 260, 145-151.

Heath, R.B., Karpe, F., Milne, R.W., Burdge, G.C., Wootton, S.A., Frayn, K.N., 2003. Selective partitioning of dietary fatty acids into the VLDL TG pool in the early postprandial period. J. Lipid Res. 44 (11), 2065-72.

Jensen, R. G., Ferris, A. M., Lammi-Keefe, C.J., 1991. The composition of milk fat. J. Dairy Sci., 74, 32283243 
Keogh, J., Wooster, T., Golding, M., Day, L., Otto, B., Clifton, P., 2011. Slowly and rapidly digested fat emulsions are equally satiating but their triglycerides are differentially absorbed and metabolized in humans. J. Nutr. 141 (5), 809-815.

Lambert, J.E., Parks, E.J., 2012. Getting the label in: practical research strategies for tracing dietary fat. Int. J. Obes. Suppl. 2 (Suppl 2), S43-50. doi: 10.1038/ijosup.2012.22.

Lopez, C., Lavigne, F., Lesieur, P., Bourgaux, C., Ollivon, M., 2001. Thermal and structural behavior of milk fat. I. Unstable species of anhydrous milk fat. J. Dairy Sci. 84, 756-766.

Michalski, M.C., Genot, C., Gayet, C., Lopez, C., Fine, F., Joffre, F., Vendeuvre, J.L., Bouvier, J., Chardigny, J.M., Raynal-Ljutovac, K. 2013. Steering Committee of RMT LISTRAL. Multiscale structures of lipids in foods as parameters affecting fatty acid bioavailability and lipid metabolism. Prog. Lipid Res. 52(4), 354-373. doi: 10.1016/j.plipres.2013.04.004.

Minekus, M., M. Alminger, P. Alvito, S. Ballance, T. Bohn, C. Bourlieu, F. Carriere, R. Boutrou, M. Corredig, D. Dupont, C. Dufour, L. Egger, M. Golding, S. Karakaya, B. Kirkhus, S. Le Feunteun, U. Lesmes, A. Macierzanka, A. Mackie, S. Marze, D. J. McClements, O. Menard, I. Recio, C. N. Santos, R. P. Singh, G. E. Vegarud, M. S. Wickham, W. Weitschies, and A. Brodkorb. 2014. A standardised static in vitro digestion method suitable for food - an international consensus. Food Funct 5: 1113-1124.

Mitchell, D. A., J. A. Rodriguez, F. Carriere, J. Baratti, and N. Krieger. 2008. An analytical method for determining relative specificities for sequential reactions catalyzed by the same enzyme: application to the hydrolysis of triacylglycerols by lipases. J Biotechnol 133: 343-350.

Petrut, R., Blecker, C., Van Hoed, V., Dombree, A., Danthine, S., 2016. The impact of emulsification and whipping on fat crystallization behavior: a comparative study between anhydrous milk fat and a lauric fat. Int. J. Research in Engineering and Technology 5 (6), eISSN: 2319-1163 - pISSN: 2321-7308. 
Ten Grotenhuis, E., van Aken, G., van Malssen, K., Schenk, H., 1999. Polymorphism of milk fat studied by differential scanning calorimetry and real-time X-ray powder diffraction. J. Am. Oil Chem. Soc. 76, 10311039.

Truong, T., Bansal, N., Sharma, R., Palmer, M., Bhandari, B., 2014. Effects of emulsion droplet sizes on the crystallization of milk fat. Food Chem. 145, 725-735.

Tzompa-Sosa, D., Ramel, P., van Vanlenberg, H., van Aken, G., 2016. Formation of $\beta$ Polymorphs in Milk Fats with Large Differences in Triacylglycerol Profiles. J. Agric. Food Chem. 64, 4152-4157.

Vors, C., Pineau, G., Gabert, L., Drai, J., Louche-Pélissier, C., Defoort, C., Lairon, D., Désage, M., Danthine, S., Lambert-Porcheron, S., Vidal, H., Laville, M., Michalski, M.C., 2013. Modulating absorption and postprandial handling of dietary fatty acids by structuring fat in the meal: a randomized crossover clinical trial. Am. J. Clin. Nutr. 97(1), 23-36. doi: 10.3945/ajen.112.043976.

Vors C, Pineau G, Drai J, Meugnier E, Pesenti S, Laville M, Laugerette F, Malpuech-Brugère C, Vidal H, Michalski MC. 2015. Postprandial Endotoxemia Linked With Chylomicrons and Lipopolysaccharides Handling in Obese Versus Lean Men: A Lipid Dose-Effect Trial. J Clin Endocrinol Metab. 100(9):3427-35. 


\section{Figure Captions}

Figure 1. Example of a DSC crystallization curve (cooling rate $-10^{\circ} \mathrm{C} / \mathrm{min}$ ) and of a DSC melting curve (Heating rate $5^{\circ} \mathrm{C} / \mathrm{min}$ )

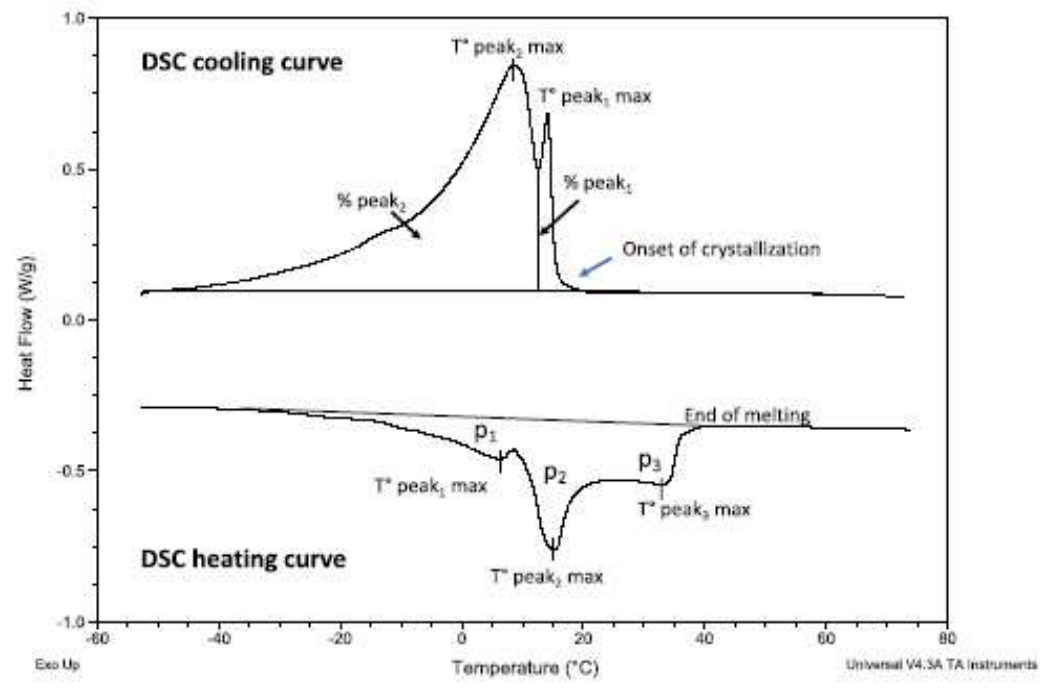


Figure 2. Thermal profile undergone by the fat samples during their preparation and in conditions mimicking digestive tract. Step 1: cooling at $-1^{\circ} \mathrm{C} / \mathrm{min}$; step 2: isothermal period at $4{ }^{\circ} \mathrm{C}$; step 3: similar to food ingestion; step 4: similar to food digestion.

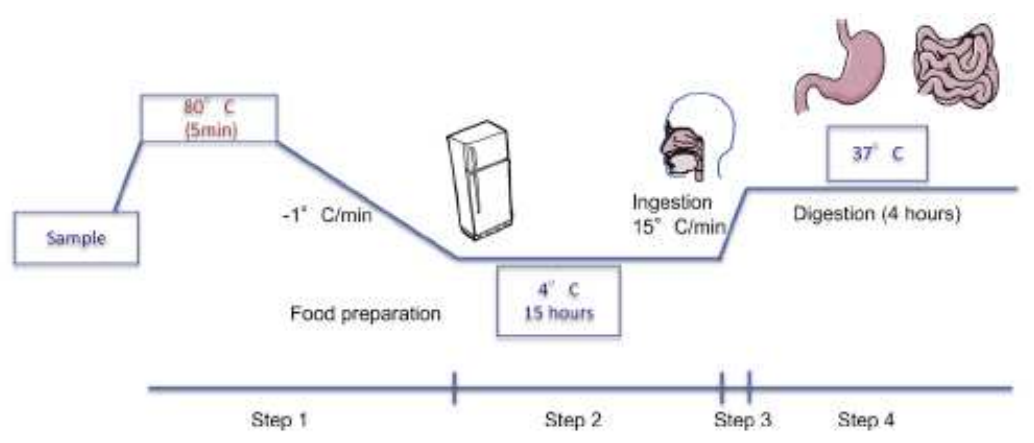


Figure 3. DSC melting profiles $\left(\mathbf{A}=\right.$ cooling curves recorded at $-10^{\circ} \mathrm{C} / \mathrm{min}, \mathbf{B}=$ heating curves recorded at $5^{\circ} \mathrm{C} / \mathrm{min}$ ) of native AMF (curve 1), AMF containing $1.5 \%$ external TAGs as tracers (curve 2), AMF containing 5.7\% external TAGs as tracers (curve 3). NB: The tracer TAG mixure was composed of PPP, OOO and CCC in a $3: 2.1: 0.9$ ratio.

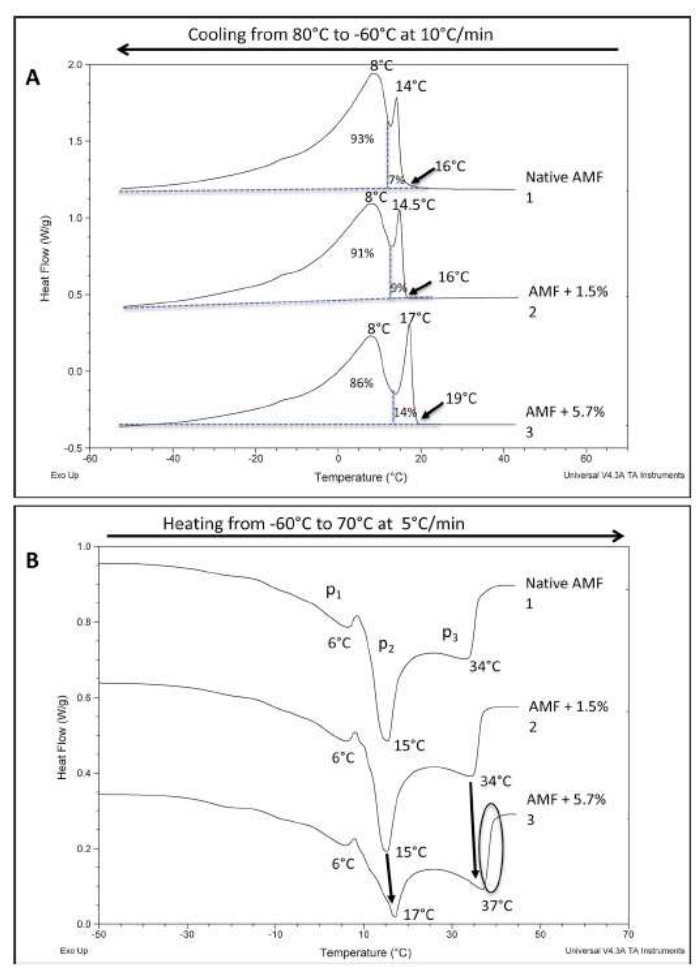


Figure 4. DSC melting profiles $\left(\mathbf{A}=\right.$ cooling curves recorded at $-10^{\circ} \mathrm{C} / \mathrm{min}, \mathbf{B}=$ heating curves recorded at $15^{\circ} \mathrm{C} / \mathrm{min}$ ) of native AMF (curve 1), AMF containing $1.5 \%$ external TAGs as tracers (curve 2), AMF containing 5.7\% external TAGs as tracers (curve 3). NB: The tracer TAG mixure was composed of PPP, OOO and CCC in a $3: 2.1: 0.9$ ratio.

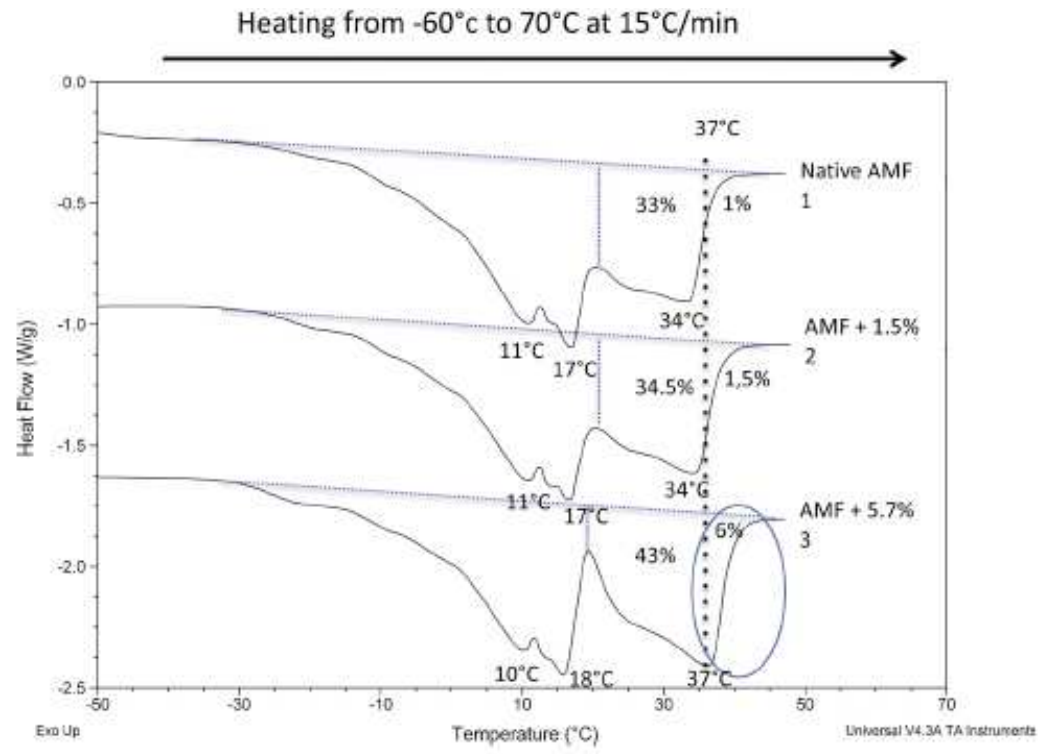


Figure 5. DSC melting profiles $\left(\mathbf{A}=\right.$ cooling curves recorded at $-1^{\circ} \mathrm{C} / \mathrm{min}, \mathbf{B}=$ heating curves recorded at $15^{\circ} \mathrm{C} / \mathrm{min}$ ) of native $\mathrm{AMF}$ (curve 1), AMF containing $1.5 \%$ external TAGs as tracers (curve 2), AMF containing 5.7\% external TAGs as tracers (curve 3). A zoom corresponding to an overlapping of the three curves is also presented. NB: The tracer TAG mixure was composed of PPP, OOO and CCC in a $3: 2.1: 0.9$ ratio.

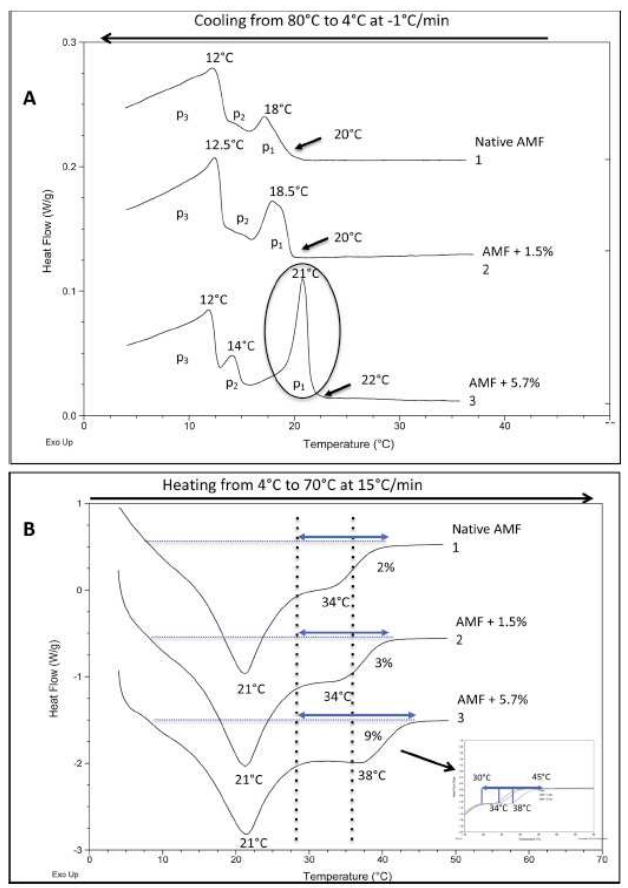


Figure 6. (A) DSC melting profiles (heating curves recorded at $15^{\circ} \mathrm{C} / \mathrm{min}$ ) of native AMF (curve 1), AMF containing 1.5\% external TAGs (curve 2), AMF containing 5.7\% external TAGs as tracers (curve 3). (B) Comparison between DSC melting profiles of native AMF (curve 1), AMF containing 1.5\% external TAGs (curve 2), AMF containing 5.7\% external TAGs as tracers (curve 3) obtained without and with the isothermal period at $37^{\circ} \mathrm{C}$ (heating rate $15^{\circ} \mathrm{C} / \mathrm{min}$ ). $N B$ : The tracer TAG mixure was composed of PPP, OOO and $\mathrm{CCC}$ in a $3: 2.1: 0.9$ ratio.

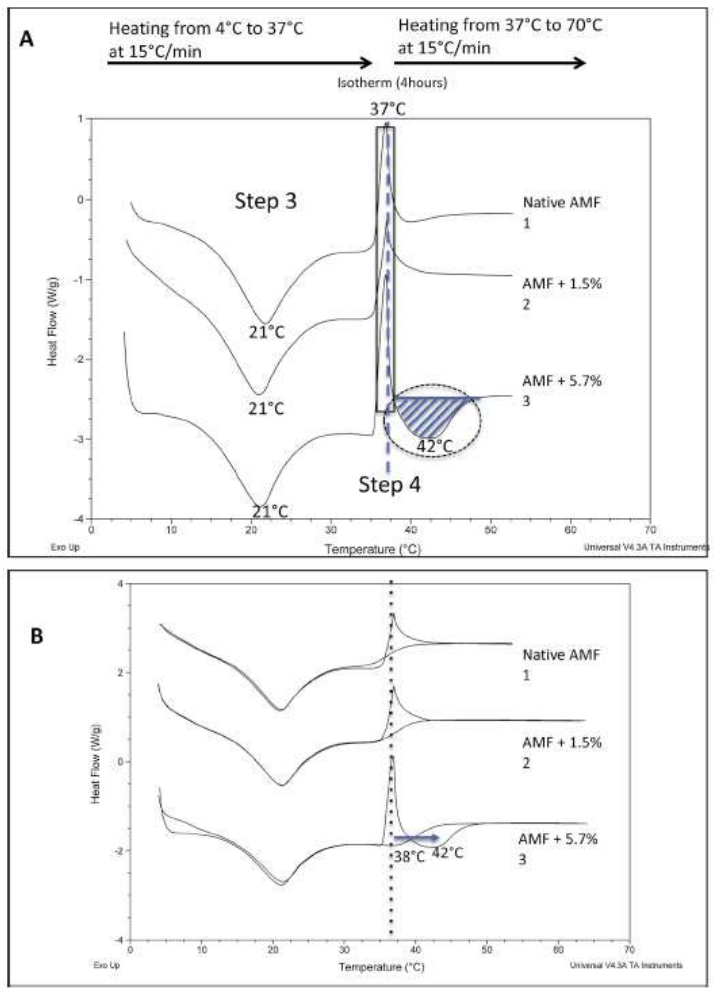


Figure 7. (A) Powder $\mathrm{XRD}$ patterns obtained at $4^{\circ} \mathrm{C}$ after cooling the fats from $80^{\circ} \mathrm{C}$ to $4^{\circ} \mathrm{C}$ at $-1^{\circ} \mathrm{C} / \mathrm{min}(1=$ AMF, $2=\mathrm{AMF}+1.5 \%$ tracers, $3=\mathrm{AMF}+5.7 \%$ tracers). $(\mathbf{B})$ Powder $\mathrm{XRD}$ patterns obtained at $4{ }^{\circ} \mathrm{C}$ after $15 \mathrm{~h}$ at that $\mathrm{T}^{\circ}(1=\mathrm{AMF}, 2=\mathrm{AMF}+1.5 \%$ tracers, $3=\mathrm{AMF}+5.7 \%$ tracers $) .(\mathrm{C})$ Powder $\mathrm{XRD}$ patterns obtained during the heating from $4^{\circ} \mathrm{C}$ to $37^{\circ} \mathrm{C}$ at $15^{\circ} \mathrm{C} / \mathrm{min}(1=\mathrm{AMF}, 2=\mathrm{AMF}+1.5 \%$ tracers, $3=\mathrm{AMF}+5.7 \%$ tracers $)$. (D) Powder XRD patterns obtained at $37^{\circ} \mathrm{C}$ after 4 hours at that $\mathrm{T}^{\circ}(1=\mathrm{AMF}, 2=\mathrm{AMF}+1.5 \%$ tracers, $3=\mathrm{AMF}+5.7 \%$ tracers). (E) Powder XRD patterns collected during the isothermal period at $37^{\circ} \mathrm{C}$ for sample “AMF+5.7\% tracers". NB: The tracer TAG mixure was composed of PPP, OOO and CCC in a $3: 2.1: 0.9$ ratio.
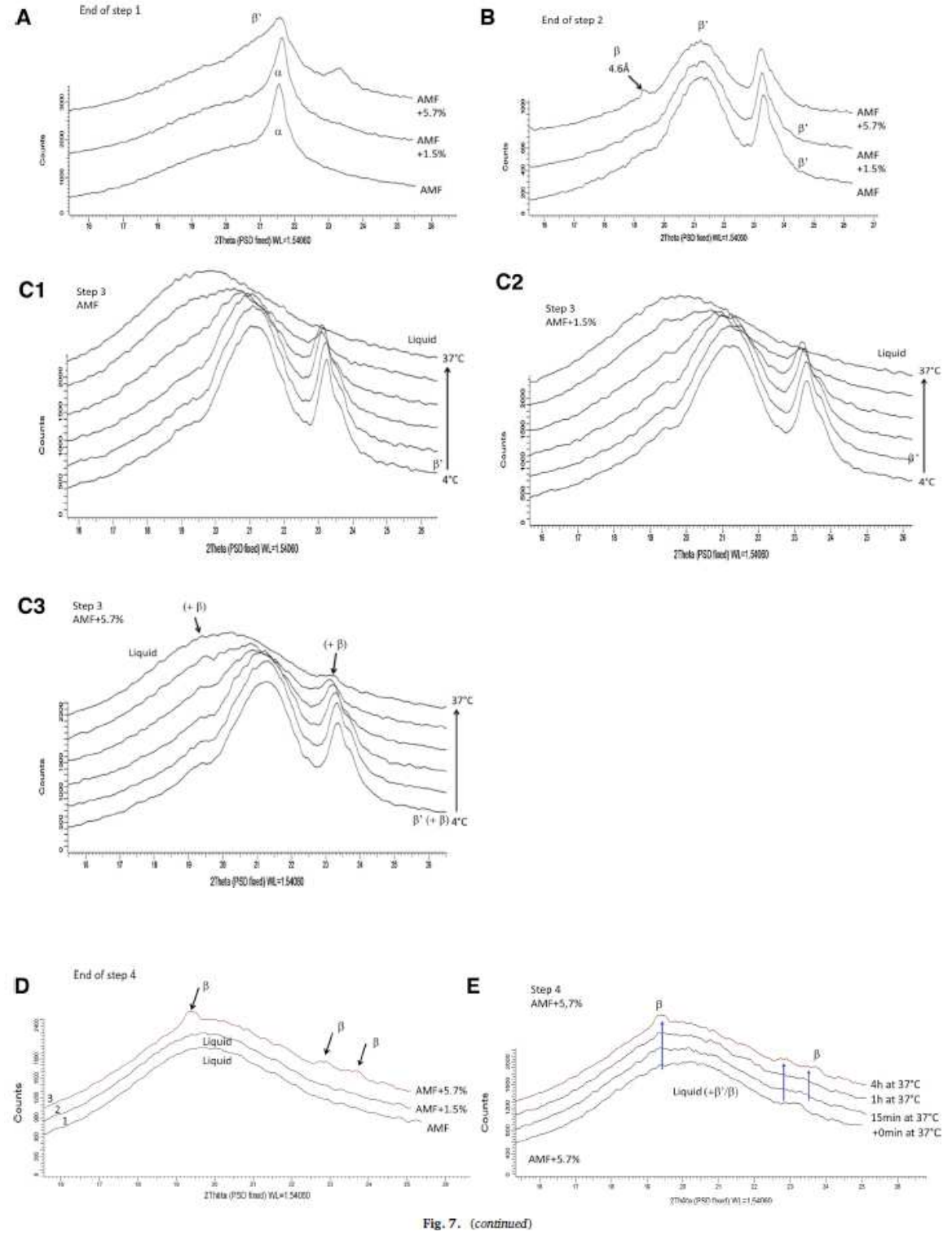
Figure 8. Particle size distribution of emulsions made with 1) AMF \& 2) AMF enriched in $1.5 \%$ of tracers after $15 \mathrm{~h}$ at $4^{\circ} \mathrm{C} . N B$ : The tracer TAG mixure was composed of PPP, OOO and CCC in a $3: 2.1: 0.9$ ratio.

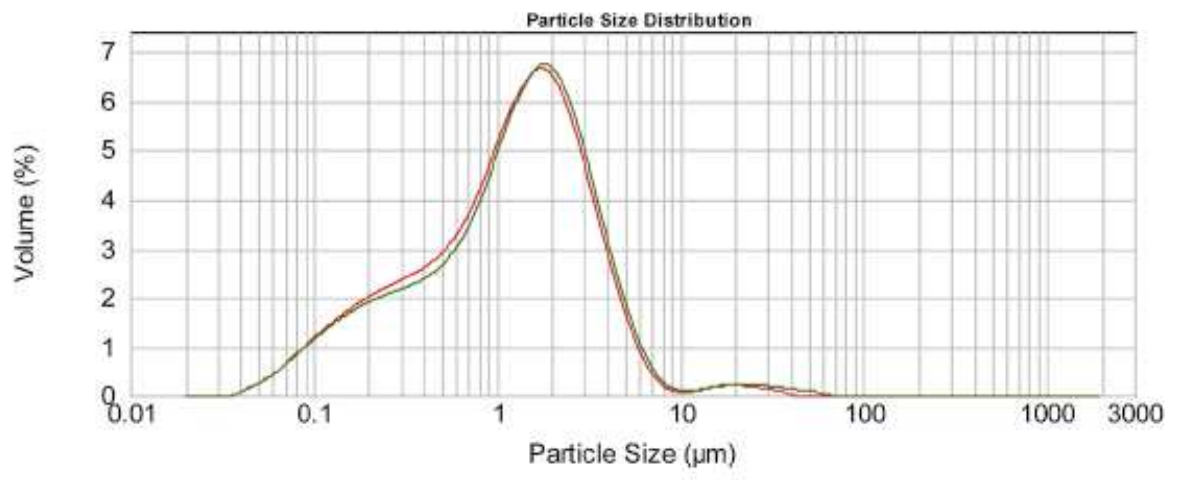


Figure 9. DSC melting profiles of the emulsions made with native AMF (curve 1), AMF containing 1.5\% tracers (curve 2) (heating rate $15^{\circ} \mathrm{C} / \mathrm{min}$ ). $N B$ : The tracer TAG mixure was composed of PPP, OOO and CCC in a $3: 2.1: 0.9$ ratio.

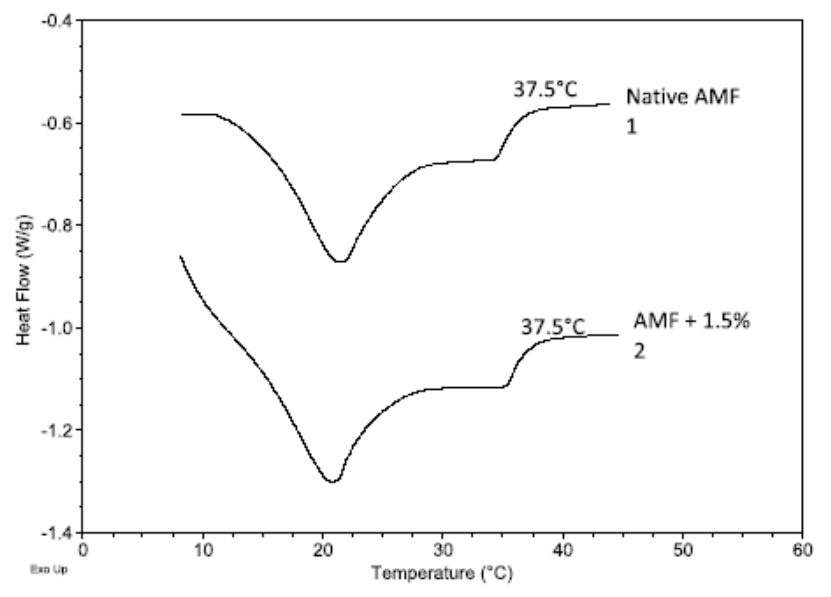


Figure 10. Effect of tracers on in vitro lipolysis of dietary fat (here anhydrous milkfat, AMF). (A) Evolution of the concentration of free fatty acids released by pancreatic lipase during in vitro lipolysis, at $37^{\circ} \mathrm{C}$ and $\mathrm{pH}=6.25$, of AMF containing $0 \%$ ( $\mathrm{n}=8$ assays), $1.5 \%$ ( $\mathrm{n}=7$ assays) or $5.7 \%$ of tracers ( $\mathrm{n}=6$ assays). Standard error (s.e.m.) bars are shown in one direction only for clarity. The star indicates the time range where the interaction between time and tracer concentration is significant (z-tests on the coefficients of the mixeddesign ANOVA with a Bonferroni-corrected threshold of 0.05/183)..Inset: Detail of lipolysis products at $\mathrm{t}=20$ minutes, measured by TLC-FID and expressed as the fraction of acyl chains either esterified as TAG, as DAG or as MAG, or not esterified (FFA). (B) Effect of tracer concentration on the lag time, defined as the intersection of the $\mathrm{x}$-axis with the tangent with the steepest slope. Stars indicate significant differences between tracer concentrations (Tukey's post-hoc test, *** $\mathrm{p}<0.001, * * \mathrm{p}<0.01, * \mathrm{p}<0.05$ ). (C) Lipolysis products as a function of hydrolysis rate. The y-axis is the fraction of acyl chains respectively esterified as triacylglycerols (TAG), diacylglycerols (DAG), monoacylglycerols (MAG), or not esterified (free fatty acids). The $\mathrm{x}$-axis is the hydrolysis rate, defined as the fraction of acyl chains that are not esterified anymore (see Methods). Data are shown as mean \pm s.e.m of two assays per tracer concentration, sampled every 10 minutes and analyzed by TLC-FID. Dotted lines are polynomial fits for visual guidance only. NB: The tracer TAG mixture was composed of PPP, OOO and CCC in a $3: 2.1: 0.9$ ratio. 
A

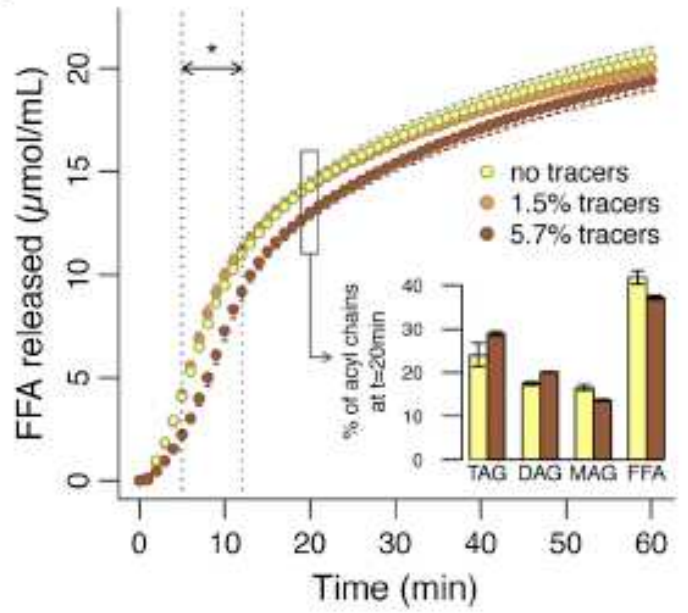

B

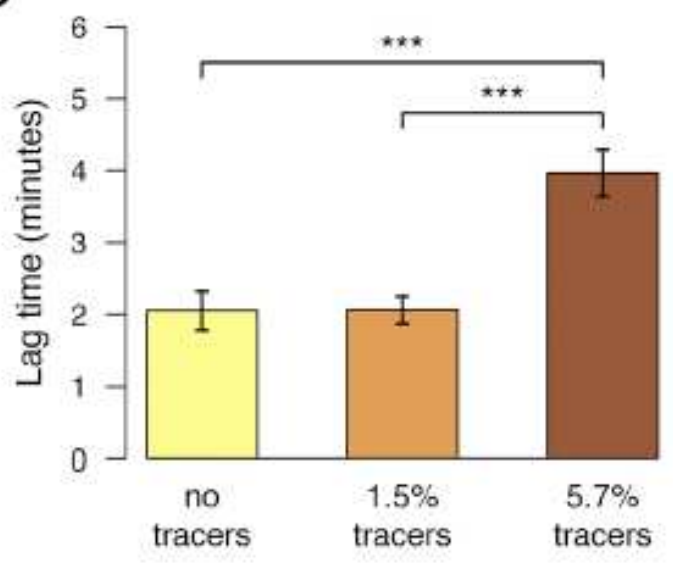

C

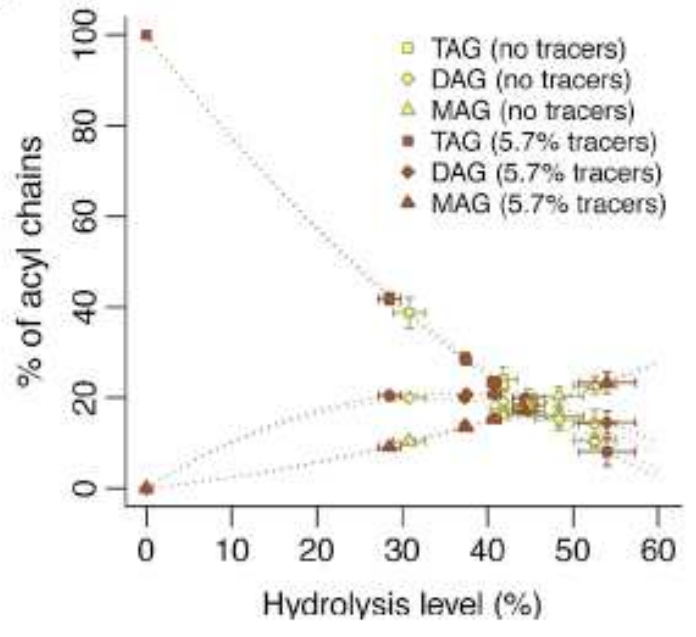

